Barrientos, Mónica. No hay armazón que la sostenga. Entrevistas a Diamela Eltit. Talca: Editorial Universidad de

\title{
Barrientos, Mónica. No hay armazón que la sostenga. Entrevistas a Diamela Eltit. Talca: Editorial Universidad de Talca, 2018, 487 páginas.
}

\author{
Esteban Rodríguez Moya*
}

Una voz con autoridad para hablar de la obra realizada por la escritora chilena Diamela Eltit es la de Mónica Barrientos Olivares. Barrientos es $\mathrm{PhD}$ in Hispanic Languajes \& Literature de la Universidad de Pittsburg, editora de Catedral Tomada: revista de crítica literaria latinoamericana de la misma universidad y también profesora de la Universidad Autónoma de Chile. Además, ha centrado su carrera académica en investigar las características que explican la producción literaria en Chile durante la dictadura y los años posteriores a ésta, poniendo especial énfasis en la obra eltitiana. Precisamente, es en esta línea donde presenta un conjunto de entrevistas que lleva por nombre:No hay armazón que la sostenga. Entrevistas a Diamela Eltit, una serie de conversaciones con la escritora nacional publicadas en diversos medios literarios y académicos, centradas específicamente en los tópicos constantes que han definido su carrera, en conjunto con los procesos de escritura asociados a sus obras más novelescas y también a aquellos escritos con un carácter más cultural.

En el marco de un análisis del contenido ofrecido por No hay armazón que la sostenga, encontramos poco más de una cuarentena de entrevistas ordenadas en cinco grupos, a saber,"La pulsión escritural", "La resistencia

\footnotetext{
* Estudiante de Doctorado en Ciencias Humanas en la Universidad de Talca, Chile. Magíster en Ciencias Religiosas y Filosóficas por la Universidad Católica del Maule, Chile. Correo electrónico: erodriguez631@gmail.com
} 
orgánica", "Performáticas corporales", "Narrativas y puesta en discurso", y, por último, "Arte, vida y comunidad". Simultáneamente, Barrientos añade una presentación al comienzo, la que lleva por nombre: "Entrevistas a Diamela Eltit: hacia un diálogo comunitario", apartado que, como es característico en este tipo de publicaciones, sirve como un espacio para dar cohesión a todo el texto. En este sentido, es relevante detenerse en algunas ideas que se exponen en la presentación, especialmente en lo que concierne es este llamado "diálogo comunitario", pues ayuda a comprender la relevancia del libro en su globalidad. La investigadora parte señalando la relevancia que tiene la entrevista literaria y académica realizada a los escritores en el mundo de hoy, pues ayuda a descubrir la trastienda que existe bajo los procesos creativos, saciando esas ganas de regresar o volver al autor que surge en los lectores o consumidores de literatura. Conjuntamente, Barrientos destaca que la entrevista de este tipo, ajena a elementos personales, ayuda a contextualizar al escritor entrevistado, a descubrir su vínculo con el contexto sociocultural, intelectual y artístico que le rodea. Todo esto conduce a la compiladora a concluir que la entrevista forma parte de la obra misma del escritor entrevistado, lo cual conlleva un tipo de diálogo comunitario, pues abre al lector, y espectador de la entrevista, hacia un espacio donde no juega un rol meramente pasivo. En efecto, por medio de la entrevista se da una interacción y comunicación indirecta con el autor, ya que permite al lector de éste identificarse con algunas de las preguntas y respuestas enunciadas, acercándose así a la subjetividad creadora bajo los escritos que forman una obra, completando con ello la obra misma.

Por otra parte, una mirada detallada de los apartados en que se agrupan los diálogos sostenidos con la escritora nacional, lleva a constatar diversos elementos asociados a su obra, además de algunas anécdotas que si bien no alcanzan el ámbito de lo personal, tienen impacto en un grado diverso dentro de su producción literaria. Es así como en el primero de ellos: "La pulsión escritural", encontramos una preocupación por los factores que intervienen en el desarrollo de la escritura llevada a cabo por Eltit. Se apunta como eje central la recuperación de una estética marginal (muchas veces femenina o latinoamericana) frente a lo socioculturalmente hegemónico, neoliberal y, 
en ocasiones, tradicional. Todo esto se refleja en obras como Por la Patria o Mano de obra. Simultáneamente, en las respuestas compiladas en este apartado también se destaca la "libertad" de los personajes que surgen en la obra eltitiana, la escritora nacional los deja fluir y solo están sujetos a una estilización posterior a la propia historia de vida de cada uno de ellos, casi al estilo creativo que tenían los poetas en la antigüedad según Sócrates. Las entrevistas presentes en el segundo conjunto: "La resistencia orgánica", se refieren a la corporalidad como motivo constante dentro de las obras de Diamela Eltit, provocando que en las conversaciones de este grupo aparezca continuamente la marginalidad, tanto en tiempos de dictadura como en momentos posteriores a la misma, la que tiende a alcanzar lo corporal, degradándolo. Esto se refleja especialmente a través del trato que recibe el cuerpo femenino dentro de la novela Fuerzas Especiales. No obstante y como solución, también se plantea dentro de las respuestas que la literatura es una forma de recuperación del cuerpo, pues es entendida por la escritora chilena como una forma de resistencia. El tercer conjunto de entrevistas, que lleva por nombre "Performáticas corporales", vuelve al tópico del cuerpo, pero esta vez destacándolocomo material social con alcance político. En los diálogos que contiene, Diamela Eltit señala que solo a través de una escritura fragmentaria, catalogada en múltiples ocasiones de antinovelesca y vanguardista, se puede captar aquello que es indecible a través de una narrativa tradicional. Por medio de fragmentos, o episodios breves, salen a la luz la marginalidad y lo corporal en sus distintas formas: social, política y biológica. Así pues, y según lo que plasma la escritora chilena en sus palabras, el carácter performático que tiene su obra (al referirse constantemente al cuerpo) tiene como base la participación que Eltit tuvo dentro del CADA o Colectivo de Acción de Arte, desde los años 1979 a 1985. Actividad artística encargada de recuperar la ciudad como lugar público y que realizaría junto a Fernando Balcells, Raúl Zurita, Lotty Rosenfeld y Juan Castillo. El cuarto compilado de entrevistas, denominado "Narrativas y puesta en discurso", se centra en obras específicas de Diamela Eltit, sobre todo en las más tempranas como Lumpérica, Vaca Sagrada y El Cuarto Mundo, además de referirse también de manera especial a sus escritos más culturales, 
tales como El Padre mío, que refleja la visión económica de un esquizofrénico entrevistado por la misma Eltit, y El Infarto del Alma, un libro compuesto de relatos y fotografías (estas últimas a cargo de Paz Errázuriz) donde se expresa la experiencia del amor entre pacientes dentro del hospital psiquiátrico de la ciudad de Putaendo. Si bien es cierto que este grupo de entrevistas vuelven a destacar los núcleos o la sintaxis que caracterizan a la obra de Diamela Eltit a partir de Lumpérica, teniendo la marginalidad y lo femenino como pilares fundamentales, también se establece que sus escritos culturales apelan a una descripción de los lugares marginales, alejándose del simbolismo impregnado en el resto de su obras más narrativas. Por último, en las entrevistas reunidas bajo el nombre de"Arte, vida y comunidad", las conversaciones pasan, por momentos, a convertirse en una suerte de debates o contrapuntos entre las ideas de Diamela Eltit y otros intelectuales, específicamente cuando Jean Franco y Carlos Monsiváis se encuentran en la posición de la interlocución. En este contexto, una de las ideas llamativas de la escritora chilena corresponde a la capacidad de absorción que el neoliberalismo posee para integrar las contrapropuestas que le son distintas. En efecto, a ojos de Eltit, todo pasa en mayor a menor medida a formar parte del mercado, esto provoca la necesidad de rescatar la estética de los microespacios distintos y fragmentarios y que son objeto del desplazamiento y la censura.

En perspectiva, uno de los puntos fuertes de No hay armazón que la sostenga. Entrevistas a Diamela Eltit, es el apoyo que presta para comprender de modo global la obra de la escritora en cuestión. Esto es algo que Barrientos deja claro en la presentación del libro, al sostener que las entrevistas forman parte de la obra de un autor. De este modo, el compilado de conversaciones funciona como una herramienta a la hora de interpretar y comprender alguna obra específica de Diamela Eltit, formando parte de lo que clásicamente se denomina como círculo hermenéutico, donde la parte ayuda a comprender el todo, pero donde a su vez, el todo, lugar en el cual se inserta No hay armazón que la sostenga, ayuda a comprender la parte. No obstante, y a pesar de implicar un importante auxiliar a nivel hermenéutico, el texto podría exhibir una edición más depurada que sintetizara aún más su contenido. En 
efecto, existen en él muchas ideas que se repiten a lo largo de las respuestas que entrega la escritora chilena, entre estas destacan: la independencia de los personajes al redactar una obra, la precarización de la corporalidad y lo femenino en un contexto neoliberal, la necesidad de rescatar la estética y los discursos presente en los lugares marginados, la influencia que jugó en su obra la participación dentro del CADA desde fines de los 70 hasta mediados de los 80, la naturaleza fragmentaria o antinovelesca de su obra, y finalmente, el talante político que se le puede otorgar a la misma. De este modo, y teniendo las ideas mencionadas en consideración, podrían omitirse las respuestas reiterativas respecto de las mismas, dejando solo aquellas que se estimen como relevantes o que representen una síntesis de las restantemente similares. Así, se resumirían y aclararían, de mejor manera, las particularidades que definen a la obra de Eltit, a pesar de que, como reza el título del compilatorio hecho por Barrientos, no exista un "armazón" o estructura que la sostenga o delimite, debido a lo rupturista de su escritura. 